\title{
Expression of the Insulin-like Growth Factor system in first and second trimester human embryonic and fetal gonads
}

Linn Salto Mamsen ${ }^{1 *}$, Zafeiri Aikaterini ${ }^{2 *}$, Jane Alrø Bøtkjær ${ }^{1}$, Jonna Hardlei Rasmussen ${ }^{1}$, Erik Ernst ${ }^{3}$, Claus Oxvig ${ }^{4}$, Paul A. Fowler ${ }^{2}$, Claus Yding Andersen ${ }^{1}$

${ }^{1}$ Laboratory of Reproductive Biology, The Juliane Marie Centre for Women, Children and Reproduction, Copenhagen University Hospital, Copenhagen University, Rigshospitalet, 2100 Copenhagen, Denmark

${ }^{2}$ Institute of Medical Sciences, School of Medicine, Medical Sciences \& Nutrition, University of Aberdeen, Foresterhill Aberdeen AB25 2ZD, Scotland

${ }^{3}$ Department of Gynaecology and Obstetrics, Regional Hospital Horsens, 8700 Horsens, Denmark

${ }^{4}$ Department of Molecular Biology and Genetics, University of Aarhus, Aarhus, Denmark

*Contributed equally and are considered shared first authors

(C) Endocrine Society 2020. All rights reserved. For permissions, please e-mail: journals.permissions@oup.com jc.2020-01559 See https://academic.oup.com/endocrinesociety/pages/Author_Guidelines for Accepted Manuscript disclaimer and additional information. 
Disclosure Summary: The authors have nothing to disclose

Financial Support: This work was supported by The Medical Research Council [MR/L010011/1 to PAF] and the European Community's Seventh Framework Programme (FP7/2007-2013) [under grant agreement no 212885 to PAF], BBSRC/EASTBIO (to AZ), ESHRE supported the ReproUnion fellowship (to AZ), Rigshospitalets Forskningspuljer (to LSM), and ReproUnion 1.0 (to LSM). 


\section{Abstract}

Context: Insulin-like Growth Factor (IGF) signaling is crucial for sex differentiation and development of Leydig and Sertoli cells in fetal mice testes. No such information is available for human embryonic and fetal testes and ovaries.

Objective: To investigate presence and activity of the IGF signaling system during human embryonic and fetal ovarian and testicular development.

Design: Human embryonic and fetal gonads were obtained following legal terminations of pregnancies. Gene expression was assessed by microarray and qPCR transcript analyses. Proteins of the IGF system components were detected with immunohistochemistry (IHC) and immunofluorescence (IF) analyses. Specimens were included between 2010-2017.

Setting: University Hospital.

Patients/Participants: Ovaries and testes from a total of 124 human embryos and fetuses aged 5-17 post conception weeks ( $\mathrm{pcw}$ ) were obtained from healthy women aged 16-47 years resident in Denmark or Scotland.

Main Outcome Measures: Gene expression analysis using microarray was performed in $\mathbf{4 6}$ specimens and qPCR analysis in 56 specimens, both sexes included. Protein analysis included 22 specimens (11 ovaries, 11 testes).

Results: IGF system members were detected in embryonic and fetal testes and ovaries, both at gene transcript and protein level. A higher expression of IGF regulators was detected in testes than ovaries, with a preferred localization to Leydig cells. 
Conclusions: These data indicate that the IGF system is active during very early gestation where it may have a regulatory role in Leydig cells.

Key words: Human gonadal development, IGF signaling, stanniocalcins, PAPP-A, first and second trimester gonads 


\section{Introduction}

The insulin-like growth factor (IGF) signaling system is a key mediator of cell growth, proliferation, survival and metabolism throughout the body (1-3). The ligands, IGF1 and IGF2, signal through the cell surface IGF receptors type 1 (IGFR1) and the insulin receptor (INSR) $(4,5)$. Signal transduction is performed by the free ligand and the bioactivity of IGFs is tightly regulated by IGF binding proteins (IGFBP-1 to -6), that antagonize receptor binding, but prolong circulatory IGF half-life (6,7) (Fig. 1).

IGFs become bioactive when released from their binding proteins by different proteinases including Pregnancy-Associated Plasma Protein-A (PAPP-A) that specifically cleaves three of the six IGFBPs (i.e. IGFBP-2, IGFBP-4, and IGFBP-5) and secures release of IGFs in the vicinity of cell surface, close to the receptor (8-10). The proteolytic activity of PAPP-A is inhibited by stanniocalsin-1 and -2 (STC1, STC2), leading to downregulation of IGF signaling $(11,12)$ (Fig. 1). Information on the IGF system and its impact during embryonic and fetal development is primarily obtained from murine models. Mice deficient in Igf1r or Insr exhibit significant growth retardation and delay in sex differentiation $(13,14)$. Moreover, sex reversal was observed in XY testes from Igf1r and Insr knockout mice, suggesting that IGF signaling is required for testis differentiation in mice $(14,15)$. Reduced Sertoli cell proliferation and sperm production occurred when Igf1r and Insr were specifically inactivated in mouse Sertoli cells, emphasizing an important role of IGF signaling in Sertoli cell proliferation and sperm production in mice (16-18). The insulin receptor substrate (IRS) proteins are key mediators of insulin and insulin-like growth factor (IGF) signaling, and deletion of Irs2 causes reduced testicular weight, fewer, and abnormal, Sertoli and sperm cells, indicating that Ins2 is vital for murine testicular development (19). Igf1 is expressed in testes of embryonic mice and Igf1 regulates somatic cell proliferation and promotes steroidogenesis, indicating that Igf1 is important for development of the male phenotype and fertility in mice $(20,21)$. A recent study on spermatogonial stem cells 
indicated a vital role of Igf1 in mouse spermatogenesis, since it was found to decrease germ cell apoptosis and increase their density in culture (22).

There is only limited information of the importance of IGF signaling during early development in humans. Neonatal testes show high expression levels of IGF2 and IGF1R in Leydig cells, suggesting that IGF signaling affects Leydig cell differentiation (23). IGF signaling has been reported to be essential for postnatal human testicular descent $(24,25)$. Expression of IGF2 was decreased in both human testis and ovaries in midterm fetuses (26), although the expression was significantly higher in testes than ovaries This suggests that IGF2 expression is regulated differently in fetal testis than in ovaries and may exert a more pronounced function in testicular than ovarian development. IGF1 expression has been detected in human fetal ovaries ( 15 and 22 post conception weeks (pcw)) (27), and may affect ovarian function during fetal life. In contrast, IGF2 is the primary ligand operating in adult human ovaries (28). In the adult human ovary, IGF signaling plays a significant role, regulating both folliculogenesis and steroidogenesis (29-32).

In human adult testes, IGF1 has been detected in Sertoli and Leydig cells, and spermatocytes $(33,34)$. The IGF1R is present on spermatocytes, early spermatids, and variably on Leydig cells, and may enhance spermatogenesis (33). Further, a positive correlation between IGF1 serum levels and testicular volume has been shown in pubertal boys, suggesting that IGF is involved in testicular growth $(18,35)$.

The aim of this study was to explore the expression of key regulators of the IGF signaling system in first and second trimester human embryonic and fetal gonads of both sexes, at both gene and protein levels. The study focuses on the changes in expression levels over time and the differences between sexes, hereby enhancing knowledge on the IGF signaling system during human gonadal development. 


\section{Materials and Methods}

This study includes male and female gonads from a total of 124 first- and second-trimester human embryos and fetuses. Gene expression analysis was performed on RNA isolated from 46 embryonic and fetal gonads (18 ovaries, 28 testes) aged 5-9 post conception weeks ( $p c w$ ) (mean \pm SD; 7.7 weeks pc \pm 1.1 ), using a Human Transcriptome Array (HTA) 2.0 microarray analysis (36). Part of the data from the microarray analysis has previously been published (36). The gene expression assays were validated with qPCR using a total of 56 first and second trimester gonads ( 21 ovaries, 34 testes) aged 5-18 pcw. Regulators of the IGF system were detected at protein level using immunohistochemistry (IHC) in a total of 22 first- and second trimester gonads (11 ovaries, 11 testes). Ovarian tissue sections with primordial follicles from one human ovary obtained from a 10.5-year-old girl with Fanconi anemia were used for positive controls.

\section{Participating women and ethical statement}

Participants were healthy women aged $16-47$ years (mean age 24.3 years, $95 \%$ of the women were between 16 and 41, one woman was 47 years of age) enrolled in Denmark and Scotland, who underwent legal elective terminations of normally-progressing pregnancies under current legislation in each country (i.e. In Denmark before $10 \mathrm{pcw}$, in Scotland before $22 \mathrm{pcw}$ ). Women from Denmark were 18-47 years of age, women from Scotland were 16-33 years old. All participants received oral and written information about the study and gave their informed consent in writing prior to inclusion in the study. Exclusion criteria included dependence on an interpreter, chronic disease, and pregnancies with known disorders. In Denmark women below the age of 18 were also excluded. Participation had no effect on the medical care received by the women. The study was in accordance with the relevant guidelines and 
regulations in Denmark and Scotland and was approved by the Scientific Ethical Committee for the Capital Region [KF(01)258206] and NHS Grampian Research Ethics Committees (REC 04/S0802/21, REC 15/NS/0123) respectively. Researchers have no access to patient identifiers and the women undergoing termination of pregnancy were therefore totally anonymized. The ovarian tissue cryopreservation scheme of the 10.5-year-old control patient with Fanconi anemia was approved by the Danish Ministry of Health (J. no. 30-1372) and by the Danish authorities to comply with the European Union tissue directive.

\section{Collection of human embryonic and fetal gonads}

Gonadal tissue from first- and second-trimester human embryos and fetuses from two separate collections were collected between 2010-2017. In Denmark, embryonic and fetal gonads were obtained following elective surgical terminations of pregnancies at Skejby University Hospital, Aarhus, Denmark as described previously (36). Second-trimester medically aborted samples were collected in Aberdeen, Scotland. Details on collection and cohort characteristics have previously been described $(37,38)$.

Gestational age was in all cases determined by crown-rump length (CRL) and head circumference (HC) for fetuses older than $14 \mathrm{pcw}$, using abdominal ultrasound. Gonads were identified and isolated using a stereomicroscope directly after the evacuation (Denmark) or dissected from intact fetuses (Scotland). Gonads obtained for gene expression analysis were snap-frozen on dry ice or placed in RNAlater ${ }^{\circledR}$ (Sigma-Aldrich, Copenhagen, Denmark) before frozen on dry ice and stored at $-80^{\circ} \mathrm{C}$ until further analysis. Gonads obtained for IHC were fixed in Bouin's solution or $4 \%$ neutral-buffered formaldehyde (NBF) and embedded in paraffin for histological analysis.

All embryos and fetuses included in the study appeared morphologically normal. Embryonic and fetal sex was first determined by gonadal morphology, and then confirmed by RT-PCR (39). 


\section{RNA extraction}

Prior to RNA extraction whole human embryonic/fetal male and female gonads were homogenized on a TissueLyser II at $4^{\circ} \mathrm{C}$ (Qiagen) in $1.0 \mathrm{~mL}$ TRI reagent ${ }^{\circledast}$ (cat. no. T9424, Sigma-Aldrich, Copenhagen, Denmark) for $2 \times 30$ second at $15 \mathrm{~Hz}$, using $0.3 \mathrm{~mm}$ stainless steel beads. Samples were further homogenized by adding $200 \mu$ chloroform followed by 15 seconds shaking and incubation at room temperature for 2-3 min. The RNA was purified using silica membrane columns following the manufactured protocol (RNeasy Plus minikit, cat. no. 74136, Qiagen, Copenhagen, Denmark).

\section{Microarray analysis}

Gene expression data from the present microarray analysis related to sex differentiation has previously been published describing the microarray methods in detail (36). Gonadal RNA samples were amplified using an Ovation Pico WTA v.2 RNA amplification system according to the manufacturer's instructions (Nugen, San Carlos, CA, USA) followed by cDNA synthesis using the Encore Biotin Module (Nugen, San Carlos, CA, USA) before hybridization to the HTA 2.0 GeneChip ${ }^{\circledR}$ (Affymetrix, Santa Clara, CA, USA). Using the Robust Multichip Average (RMA) and pre-filtering according to Bourgon and colleagues (40), the data was normalized as previously described (36). Log2 expression between 2.1 and 5 defined genes expressed in a compartment of cells and log2 expression above 5 defined genes being expressed in either all cells or abundantly in a subset of cells. The probes identifying the IGF2 gene also covered exons including in the INS gene and the expression detected represent both IGF2 and INS expression. 


\section{Quantitative real-time PCR (RT-PCR) Analysis}

RNA from embryonic and fetal gonads was converted to first-strand cDNA by the use of the High Capacity cDNA Reverse Transcriptase Kit (Applied Biosystems, Carlsbad, CA, USA) according to the manufacturer's instructions. Samples were kept on ice at all times. RT-PCR analysis was performed using TaqMan technology (Applied Biosystems), applying TaqMan Gene Expression Master Mix from Invitrogen (Invitrogen, 2012 Life Technologies Corporation) and predesigned Taq-Man Gene Expression Assays for the following genes: IGF2, IGFBP4, IGFBP5, STC1, STC2, and PAPP-A (probe-id: IGF2, Hs04188276_m1, Hs04188276_m1; IGFBP4, Hs01057900_m1; IGFBP5, Hs00181213_m1; STC1, Hs00174970_m1; STC2, Hs01063215_m1; PAPPA, Hs01032307_m1) (Invitrogen). The genes were selected based on their regulative role of IGF bioactivity. The cDNA samples were amplified in duplicates using the LightCycler 480 quantitative PCR instrument (Roche). Human glyceraldehyde 3phosphatdehydrogenase (GAPDH) was used as endogenous control (probe id. No.: 433764 F). All samples were normalized to GAPDH and the relative expression was quantified according to the Comparative CT Method (41).

\section{Immunohistochemistry}

Immunohistochemistry was performed on $5 \mu \mathrm{m}$ paraffin-embedded sections, which were deparaffinized in xylene, gradually rehydrated in ethanol $(99 \%, 96 \%$ and $70 \%)$ followed by antigen retrieval in either $10 \mathrm{mM}$ sodium citrate, $\mathrm{pH} 6$ or in $10 \mathrm{mM}$ Tris, $0.5 \mathrm{mM}$ EGTA, pH 9. Endogenous activity was inhibited using $3 \%$ peroxidase, followed by inhibition of nonspecific binding with $1 \%$ bovine serum albumin (BSA) (Sigma Aldrich, Copenhagen, Denmark). Sections were incubated with primary antibodies overnight at $4^{\circ} \mathrm{C}$ in a humid chamber; details of antibodies and conditions are given in Table 1. A secondary rabbit-anti-mouse-HRP conjugated antibody was used (Dako, Glostrup, 
Denmark) and visualised with 3.3'-diaminobenzidine tetrahydrochloride (DAB+ Substrate Chromogen System, Dako). Both Universal negative control serum ${ }^{\circledast}$ (BioCare Medical, CA, USA) and antibody dilution buffer was used in place of primary antibody as IgG-negative controls and showed no staining in all specimens, data not shown.

\section{Immunofluorescence}

To investigate the localization of PAPP-A and the Leydig cell marker CYP17A1 immunofluorescence was performed. Briefly, $5 \mu \mathrm{m}$ paraffin tissue sections were dewaxed in xylene and rehydrated in a graded ethanol series. Antigens were retrieved with Tris-EGTA buffer (10 mM Tris, 0.5 mM EGTA, pH 9) boiled in a pressure cooker for 20 min. After cooling, slides were blocked in Tris-buffered saline (TBS) with 1\% BSA (TBS: $50 \mathrm{mM}$ Tris, $150 \mathrm{mM} \mathrm{NaCl}, \mathrm{pH}$ 7.6) for $1 \mathrm{~h}$ prior to incubating with primary antibody (Table 1 ) at $4^{\circ} \mathrm{C}$ overnight. After incubation, slides were rinsed in TBS supplemented with Tween-20 (TBST) (100 mM Tris, $150 \mathrm{mM} \mathrm{NaCl}, 0.05 \%$ Tween-20, pH 7.6) and incubated with the appropriate secondary antibody for $1 \mathrm{~h}$ at room temperature. After rinse with TBST, slides were counterstained with DAPI (1:100) and mounted with Prolong Gold mounting medium (cat. No. P36930, Invitrogen).

\section{Statistical methods}

Statistical analyses of microarray and RT-PCR gene expression data were performed using a generalized linear model with a two-way interaction between embryonic/fetal sex and age. Normality checks were performed prior to each transcript data analysis. The potential for maternal age effects on RT-PCR gene expression profiles was analysed using the Pearson's correlation model. For the purpose of this study, raw data were log2 transformed for consistency. Statistical significance was set to $<0.05$ and confidence intervals ( $\mathrm{Cls}$ ) at $95 \%$ were calculated and represented graphically. All statistical analyses and generation of graphs was performed using R Software version 3.6.0 and ggplot2. 


\section{Results}

\section{Screening for IGF signaling family members}

Gene expressions in both ovaries and testes in relation to age (post conception days, pcd) are shown in Fig. 2. One-way interactions of expression with age for each sex separately and two-way interactions with age together with sex were checked for each presented gene. Expression of IGF1 mRNA increased with age in both sexes, although only statistically significant in testes $(p=0.013)$. No difference in expression was observed between the two sexes. In contrast, the INS-IGF2 expression (combined expression of insulin and IGF2) increased significantly with age in testis $(p<0.001)$ and decreased in ovaries $(\mathrm{p}=0.002)$. The IGF1R showed similar expression patterns, with a lower expression in ovaries than testes, a significant difference between the sexes was detected $(\mathrm{p}=0.044)$. Both IGF1R and INSR increased significantly across gestation in testes $(\mathrm{p}<0.001, \mathrm{p}<0.001)$, not in ovaries $(p=0.869, p=0.865)$. All IGF binding proteins (IGFBPS) $1-6$ were expressed in the first trimester gonads, with no significant difference in transcript levels between the sexes. The expression of IGFBP3 and IGFBP5 decreased significantly with age in both sexes (testes: $\mathrm{p}<0.001$, $p=0.003$; ovaries: $p=0.003, p=0.001$ ) respectively, while no changes were observed according to age for other IGFBPs. PAPP-A and PAPPA-2 both significantly decreased with age in testes and ovaries (testes $p<0.001, p<0.001 ;$ ovaries $p=0.007, p=0.014$ ), respectively. Overall, STC1 expression was higher than STC2 in both sexes. Only testicular STC1 expression increased significantly with age $(p<0.001)$ but was significantly lower $(p=0.014)$ than ovarian expression levels. There was no significant difference in the expression levels of STC2 between males and females. The downstream targets INSR, IRS1 and IRS2, were differentially expressed between the sexes. IRS1 was significantly higher $(p=0.011)$ in ovaries, while IRS2 was significantly higher $(p<0.001)$ in testes. Age differences 
were also seen, with IRS1 expression significantly decreasing across gestation in ovaries $(p<0.001)$ but not in testes, and IRS2 expression significantly increased with age in testes $(p<0.001)$ but not in ovaries. Moreover, a significantly higher IRS2 expression was seen in testes from day 53 pc and onwards compared to before day $53(p=0.01)$.

\section{Confirmation of IGF component transcripts in first and second trimester gonads}

A larger cohort of 34 male and 21 female gonads aged 5 to $17 \mathrm{pcw}$ were used to perform RT-PCRs on IGF2, IGFBP4, PAPPA, STC1 and STC2 genes (Fig. 3). We observed no correlation between maternal age and any of the reported gene expression profiles (data not shown). As seen in the previous analysis, IGF2 expression increased in males and decreased in females across gestation, resulting in significant differential expression $(p<0.001)$ between the two sexes. However, the rate of change in expression across gestation was significant only for males ( $p=0.001)$. Expression of IGFBP4 decreased significantly across gestation in both sexes $(p<0.001)$. A sex dimorphic expression pattern was observed for PAPP-A ( $\mathrm{p}=0.030)$, with an increase in males and a decrease in females across gestation. In testes, PAPP-A expression increased significantly with age $(p=0.032)$, which was not the case in ovaries $(p=0.3)$. Transcript levels for STC1 increased in males and decreased in females with significant sex $(p<0.001)$ and age differences in both males $(p<0.001)$ and females $(p=0.006)$, in agreement with the microarray. The STC2 expression was higher in ovaries than testes confirming the microarray analysis. A significant decrease in STC2 expression across gestation was observed in both testes $(p=0.01)$ and ovaries $(p=0.009)$. 


\section{Immunohistochemical analysis}

Using immunohistochemistry, expression at the protein level of key IGF regulators (IGF1R, PAPPA, STC1, STC2, IGFBP-4 and IGFBP-5) in both testes and ovaries from pcw 5-18 was then assessed. Representative images are shown in Fig. 4. The analyses were performed in ovaries from consecutive pcw 6 and 8 to 18 representing all developmental weeks, except week 7. Testes included all pcw 618. In testes, proteins of the IGF system localized primarily to Leydig cells although detection in germ and Sertoli cells was also observed (Fig. 4A). In contrast, proteins of the IGF system were generally expressed in both germ cells and somatic cells in the ovary, with no preference to a specific cell type (Fig. 4B). A tendency to a more intense straining to the germ cells was observed.

PAPP-A in second trimester testis and ovary

PAPP-A was detected in Leydig cells of a human male $17 \mathrm{pcw}$ testis. Double staining with the Leydig cell marker CYP17 confirmed that PAPP-A was primarily located outside the seminiferous tubules with expression distinctly located to Leydig cells (Fig. 5A). In the 18 pcw human fetal ovary, PAPP-A showed less specific localization. Double staining with the germ cell marker LIN28 revealed localization of PAPP-A in some germ cells along with other cell types (Fig. 5B). 


\section{Discussion}

This study describes, for the first time, expression of IGF system regulators in human ovaries and testes during embryonic and fetal life, at both gene and protein levels. These results demonstrate that IGF is potentially involved in gonadal growth and development as early as the embryonic stages around sex differentiation ( $6 \mathrm{pcw})$ and onset of male steroidogenesis $(8 \mathrm{pcw})(36,42)$. Moreover, the IGF signaling components increasing in expression with embryonic/fetal age (i.e. INS-IGF2, IGF1R, INSR, IRS2), were generally upregulated in testes compared to ovaries. In first trimester gonads, PAPP-A decreased with age in both sexes. Surprisingly, the expression in testes increased when specimens from both first and second trimester were included, indicating a biphasic $P A P P-A$ expression pattern, with downregulation in the first trimester, while there is an upregulation in second trimester. Consequently, it may be hypothesized that bioavailable IGF2 is reduced in first trimester, with a relative increase in second trimester. Methodologically the array probe detecting IGF2 also included INS, whereas the QPCR probe detected IGF2 alone. Since the expression pattern obtained with the two different methods agreed, the contribution of INS to the array expression is probably minor. The IGF binding proteins remained constant between sexes across gestation in both sexes, while STC1, and STC2 were upregulated in ovaries compared to testes in first trimester specimens. Interestingly, the STC1 expression increased significantly in second trimester testes where the expression was higher than ovaries, illustrating a significant increased STC1 expression in testes across gestation. Collectively this suggests that the IGF system is a more central regulator in testes than in ovaries during embryonic and fetal development. This is interesting since there is hardly any circulation in embryos at these early developmental stages and suggests that IGF signaling occurs via para- and autocrine mechanisms in the developing gonads. Similarly, IGF signaling in the avascular human ovarian follicles has been described $(28,43)$ emphasizing that active IGF signaling is not dependent on direct contact to the circulation. IGF1 was upregulated in both sexes across gestation, whereas IGF2 was upregulated in testes and downregulated in ovaries, indicating a more profound role for IGF2 in testes than in ovaries. 
Overall, there was good agreement between the two methods used for evaluating gonadal transcript expression of IGF signaling (i.e. microarray and qPCR analysis). The present study is retrospective and the functional role of the IGF system are not directly elucidated by these analyses. Further studies are needed to evaluate the precise regulatory effects that IGF signaling may exert on early fetal gonadal development as well as possible regulatory effects on the testicular steroidogenesis.

Our findings confirm and extend the observations by Voutilainen and Miller, who, more than three decades ago, reported IGF2 to be expressed in human fetal gonads (13-26 gestational weeks) with a higher expression in testes than ovaries (26). While Voutilainen and Miller found a decrease in IGF2 expression in testis from gestational week 13-26, we here show a significant increase from week 5$16 \mathrm{pc}$, indicating that IGF2 may be a particularly important regulator during the crucial early events of sex differentiation and onset of steroidogenesis in males, which takes place in pcw 6 and 8 , respectively $(36,42)$. Taken together, this suggests that IGF signaling is relatively upregulated in the embryonic and fetal testes as compared to the ovary, indicating that IGF signaling may play a more important regulatory role in the developing testes than in the ovary. It adults the regulation of IGF signaling components change with age $(44,45)$ and we tested whether maternal age was associated with the level of embryonic and fetal IGF gene expression, however, our data did not show any such associations.

Our gene expression analyses revealed that both STC1 and STC2 and PAPP-A were expressed in testes and ovaries, indicating that proteinase-inhibitor complex formation is possible, and that PAPPA activity may be regulated by both STC1 and STC2. It has previously been shown in mice in vitro that STC1 and STC2 inhibit the proteolytic activity of PAPP-A $(11,12)$. Moreover, PAPP-A, STC1, STC2 
and the inhibited complexes have been detected in human follicular fluids, demonstrating that complex formation occurs in adult human ovarian tissues, and suggesting that STC1 and STC2 regulate PAPP-A in the adult human ovary during folliculogenesis (43). The present study detected a significant upregulation of STC1 transcript in testes across gestation, suggesting that PAPP-A may primarily be regulated by STC1 during first and second trimester.

Gene expression of the intracellular IGF signaling mediators, IRS-1 and IRS-2, were detected in gonads of both sexes. Interestingly, IRS-1 expression was decreasing across gestation in ovaries and constantly expressed in testes while IRS-2 was increasing across gestation in testis and constantly expressed in ovaries. This indicates a sex dimorphic intracellular IGF signal transduction, with transduction increasing in testes and decreasing in ovaries with age. This illustrates that IGF regulation may be more critical in embryonic and fetal testis than in ovaries. IRS-2 increased significantly in testes from day 53 and onwards compared to the levels before day 53 , which correlates exactly with the previously reported onset of human steroidogenic onset around day 53 pc (36). This supports the hypothesis that IGF mediated signaling may affect steroidogenesis in human fetal Leydig cells, as seen in human postnatal Leydig cells (23). In the adult human testis both IRS-1 and IRS- 2 have been detected. Furthermore, IRS-1 has been detected in peritubular myoid cells and interstitial cells, which is in accordance with the high energy expenditure of these contractile cells in the adult testis (46). Irs-2is required for normal testis development in mice. Contradictorily, Irs-2 deficient mice present with abnormalities in Sertoli cells and germ cells rather than in Leydig cells (19), indicating that IGF regulation is likely to be different between the two species. However, Irs-2 has been detected in Sertoli cells, germ cells, and Leydig cells in adult rat testes, suggesting that IGF signaling may be functional in additional testicular cell type at different developmental phases. 
Our immunohistochemical analysis showed that all evaluated components of the IGF system were present at protein level in both testes and ovaries. Furthermore, in testes, the IGF components located primarily to Leydig cells, which implies that IGF signaling may exert functions in different cell compartments at various time points as well as a sex specific role in regulating fetal Leydig cells differentiation and steroidogenesis. PAPP-A and CYP17A1 (a key enzyme in androgen synthesis) were also located specifically to embryonic/fetal human Leydig cells, further supporting the hypothesis that IGF signaling may affect early steroidogenesis. These observations confirm a previous report, which also detected IGF-2, IGF1R and INSR primarily located to Leydig cells in postnatal human testes and implied that IGF signaling was involved in postnatal human testicular differentiation and steroidogenesis (23). The present study found that both IGF-1 and IGF-2 are expressed in embryonic and fetal testis. Previous studies have reported that serum IGF-1 levels correlate with testes size in children and adolescents (35) and that adult human Leydig cells, Sertoli cells, and spermatocytes express IGF-1 (33). One study found IGF-2 expressed in spermatocytes and in some Sertoli cells in adult testicular tissue (47). Further, IGF-2 correlated with the FSH receptor (FSHR) expression, implicating a paracrine control of spermatogenesis (47). A potential different regulation and function of IGFs fetal gonads than in adults require further studies to elucidate.

In summary, our data provide the first evidence that the IGF signaling system is active in human embryonic and fetal gonads of both sexes, with a relatively higher expression of most components in testes compared to ovaries. The IGF components were located primarily to Leydig cells in testis, suggesting a regulatory role in differentiation and steroidogenesis. 


\section{Limitations}

First and second trimester specimens were collected in Denmark and Scotland, respectively and geographical differences in maternal lifestyles which potentially could affect results cannot be excluded. There were no obvious differences between the Danish and Scottish participants regarding age, BMI, and rural/urban site of living. All analyses were performed in Denmark in order to maintain methodological consistency. Moreover, the data is descriptive and further studies are required for mechanistic conclusions.

\section{Acknowledgement}

Marianne Sguazzino is acknowledged for excellent technical assistance. Gabriela Gudbergsen is acknowledged for her excellent design of Fig. 1.

\section{Correspondence and Reprint Requests:}

Linn Salto Mamsen MSc, PhD, Laboratory of Reproductive Biology, Section 5712, University Hospital of Copenhagen, University of Copenhagen, Blegdamsvej 9, Rigshospitalet, 2100 Copenhagen, Denmark. E-mail: linn.salto.mamsen@regionh.dk

Data Availability: The dataset generated and/or analyzed during the current study are not publicly available but are available from the corresponding author on reasonable request. Microarray data are available with the Array Express accession number: E-MTAB-5611. 


\section{Author Contribution}

LSM designed the project, obtained embryonic and fetal specimens from the Danish cohort, was responsible for the microarray analysis, did IHC and wrote the paper. ZA collected the fetal specimens from UK, did IHC staining, statistical analysis, did qPCR analysis, and wrote the paper. JAB did the qPCR analysis and wrote the paper. JH did IHC staining. EE recruited Danish patients and evacuated embryos and fetuses. CO developed IGF related antibodies and participated writing the paper. PAF was responsible for the UK fetal cohort, designed the project. CYA designed the project and participated in writing the paper. Authors LSM, ZA, CO, PAF, and CYA were responsible for final editing and approval of the manuscript. 


\section{References}

\section{References}

1. Annunziata M, Granata R, Ghigo E. The IGF system. Acta Diabetol. 2011;48(1):1-9.

2. Baker J, Liu JP, Robertson EJ, Efstratiadis A. Role of insulin-like growth factors in embryonic and postnatal growth. Cell. 1993;75(1):73-82.

3. DeChiara TM, Efstratiadis A, Robertsen EJ. A growth-deficiency phenotype in heterozygous mice carrying an insulin-like growth factor II gene disrupted by targeting. Nature. 1990;345(6270):78-80.

4. Roith D Le. The Insulin-Like Growth Factor System. Exp Diabesity Res. 2003;4(4):205-212.

5. Frasca F, Pandini G, Scalia P, Sciacca L, Mineo R, Costantino A, et al. Insulin receptor isoform A, a newly recognized, high-affinity insulin-like growth factor II receptor in fetal and cancer cells. Mol Cell Biol. 1999;19(5):3278-3288.

6. Mohan S, Baylink DJ, Pettis JL. Insulin-like growth factor (IGF)-binding proteins in serum--do they have additional roles besides modulating the endocrine IGF actions? J Clin Endocrinol Metab. 1996;81(11):3817-3820.

7. Firth SM, Baxter RC. Cellular actions of the insulin-like growth factor binding proteins. Endocr Rev. 2002;23(6):824-854.

8. Boldt HB, Conover CA. Pregnancy-associated plasma protein-A (PAPP-A): a local regulator of IGF 
bioavailability through cleavage of IGFBPs. Growth Horm IGF Res. 2007;17(1):10-18.

9. Oxvig C. The role of PAPP-A in the IGF system: location, location, location. J Cell Commun Signal. 2015;9(2):177-187.

10. Laursen LS, Overgaard MT, Weyer K, Boldt HB, Ebbesen P, Christiansen M, et al. Cell surface targeting of pregnancy-associated plasma protein A proteolytic activity: Reversible adhesion is mediated by two neighboring short consensus repeats. J Biol Chem. 2002;277(49):47225-47234.

11. Jepsen MR, Kløverpris S, Mikkelsen JH, Pedersen JH, Füchtbauer EM, Laursen LS, et al. Stanniocalcin-2 inhibits mammalian growth by proteolytic inhibition of the insulin-like growth factor axis. J Biol Chem. 2015;290(6):3430-3439.

12. Kløverpris S, Mikkelsen JH, Pedersen JH, Jepsen MR, Laursen LS, Petersen SV, et al. Stanniocalcin-1 Potently Inhibits the Proteolytic Activity of the Metalloproteinase Pregnancy-associated Plasma ProteinA. J Biol Chem. 2015;290(36):21915-21924.

13. Baker J, Hardy MP, Zhou J, Bondy C, Lupu F, Bellvé AR, et al. Effects of an Igf1 gene null mutation on mouse reproduction. Mol Endocrinol. 1996;10(7):903-918.

14. Pitetti J-L, Calvel P, Romero Y, Conne B, Truong V, Papaioannou MD, et al. Insulin and IGF1 Receptors Are Essential for XX and XY Gonadal Differentiation and Adrenal Development in Mice. PLoS Genet. 2013;9(1):e1003160.

15. Nef S, Verma-Kurvari S, Merenmies J, Vassalli J-D, Efstratiadis A, Accili D, et al. Testis determination requires insulin receptor family function in mice. Nature. 2003;426(6964):291-295.

16. Pitetti J-L, Calvel P, Zimmermann C, Conne B, Papaioannou MD, Aubry F, et al. An Essential Role for 
Insulin and IGF1 Receptors in Regulating Sertoli Cell Proliferation, Testis Size, and FSH Action in Mice. Mol Endocrinol. 2013;27(5):814-827.

17. Froment $\mathrm{P}$, Vigier M, Nègre D, Fontaine I, Beghelli J, Cosset FL, et al. Inactivation of the IGF-I receptor gene in primary Sertoli cells highlights the autocrine effects of IGF-I. J Endocrinol. 2007;194(3):557-568.

18. Cannarella R, Condorelli RA, La Vignera S, Calogero AE. Effects of the insulin-like growth factor system on testicular differentiation and function: a review of the literature. Andrology. 2018;6(1):3-9.

19. Griffeth RJ, Carretero J, Burks DJ. Insulin receptor substrate 2 is required for testicular development. PLoS One. 2013;8(5):e62103.

20. Villalpando I, López-Olmos V. Insulin-like growth factor I (IGF-I) regulates endocrine activity of the embryonic testis in the mouse. J Steroid Biochem Mol Biol. 2003;86(2):151-158.

21. Villalpando I, Lira E, Medina G, Garcia-Garcia E, Echeverria O. Insulin-like growth factor 1 is expressed in mouse developing testis and regulates somatic cell proliferation. Exp Biol Med. 2008;233(4):419-426.

22. Yao J, Zuo H, Gao J, Wang M, Wang D, Li X. The effects of IGF-1 on mouse spermatogenesis using an organ culture method. Biochem Biophys Res Commun. 2017;491(3):840-847.

23. Berensztein EB, Baquedano MS, Pepe CM, Costanzo M, Saraco NI, Ponzio R, et al. Role of IGFs and insulin in the human testis during postnatal activation: Differentiation of steroidogenic cells. Pediatr Res. 2008;63(6):662-666.

24. Özdamar MY, Şahin S, Zengin K, Seçkin S, Gürdal M. Detection of insulin-like growth factor receptor-1 in the human cremaster muscle and its role in the etiology of the undescended testis ScienceDirect. Asian J Surg. 2019;42(1):290-296. 
25. Koskenniemi JJ, Virtanen HE, Wohlfahrt-Veje C, Löyttyniemi E, Skakkebaek NE, Juul A, et al. Postnatal Changes in Testicular Position Are Associated With IGF-I and Function of Sertoli and Leydig Cells. J Clin Endocrinol Metab. 2018;103(4):1429-1437.

26. Voutilainen R, Miller WL. Developmental and Hormonal Regulation of mRNAs for Insulin-Like Growth Factor II and Steroidogenic Enzymes. DNA. 1988;7(1):9-15.

27. Poljicanin A, Filipovic N, Vukusic Pusic T, Soljic V, Caric A, Saraga-Babic M, et al. Expression pattern of RAGE and IGF-1 in the human fetal ovary and ovarian serous carcinoma. Acta Histochem. 2015;117:468476.

28. Bøtkjær JA, Jeppesen JV, Wissing ML, Kløverpris S, Oxvig C, Mason JI, et al. Pregnancy-associated plasma protein A in human ovarian follicles and its association with intrafollicular hormone levels. Fertil Steril. 2015;104(5):1294-1301.

29. Zhou P, Baumgarten SC, Wu Y, Bennett J, Winston N, Hirshfeld-Cytron J, et al. IGF-I signaling is essential for FSH stimulation of AKT and steroidogenic genes in granulosa cells. Mol Endocrinol. 2013;27(3):511523.

30. Van Dessel HJHMT, Chandrasekher Y, Yap OWS, Lee PDK, Hintz RL, Faessen GHJ, et al. Serum and Follicular Fluid Levels of Insulin-Like Growth Factor I (IGF-I), IGF-II, and IGF-Binding Protein-1 and -3 during the Normal Menstrual Cycle. J Clin Endocrinol Metab. 1996;81(3):1224-1231.

31. Aladin Chandrasekher Y, Van Dessel HJHM, Fauser BCJM, Giudice LC. Estrogen- but not androgendominant human ovarian follicular fluid contains an insulin-like growth factor binding protein-4 protease. J Clin Endocrinol Metab. 1995;80(9):2734-2739.

32. Geisthovel F, Moretti-Rojas I, Asch RH, Rojas FJ. Expression of insulin-like growth factor-II (IGF-II) 
messenger ribonucleic acid (mRNA), but not IGF-I mRNA, in human preovulatory granulosa cells. Hum Reprod. 1989;4(8):899-902.

33. Vannelli BG, Barni T, Orlando C, Natali A, Serio M, Balboni GC. Insulin-like growth factor-1 (IGF-I) and IGF-I receptor in human testis: an immunohistochemical study. Fertil Steril. 1988;49(4):666-669.

34. Lejeune H, Sanchez P, Saez JM. Enhancement of long-term testosterone secretion and steroidogenic enzyme expression in human Leydig cells by co-culture with human Sertoli cell-enriched preparations. Int J Androl. 1998;21(3):129-140.

35. Juul A, Bang P, Hertel NT, Main K, Dalgaard P, Jørgensen K, et al. Serum insulin-like growth factor-I in 1030 healthy children, adolescents, and adults: relation to age, sex, stage of puberty, testicular size, and body mass index. J Clin Endocrinol Metab. 1994;78(3):744-752.

36. Mamsen LS, Ernst EH, Borup R, Larsen A, Olesen RH, Ernst E, et al. Temporal expression pattern of genes during the period of sex differentiation in human embryonic gonads. Nat Sci Reports. 2017;7(15961):116.

37. Walker N, Filis P, O’Shaughnessy PJ, Bellingham M, Fowler PA. Nutrient transporter expression in both the placenta and fetal liver are affected by maternal smoking. Placenta. 2019;78:10-17.

38. O’Shaughnessy PJ, Baker PJ, Monteiro a, Cassie S, Bhattacharya S, Fowler P a. Developmental changes in human fetal testicular cell numbers and messenger ribonucleic acid levels during the second trimester. J Clin Endocrinol Metab. 2007;92(12):4792-4801.

39. Nakahori Y, Hamano K, Iwaya M, Nakagome Y. Sex identification by polymerase chain reaction using X-Y homologous primer. Am J Med Genet. 1991;39(4):472-473. 
40. Bourgon R, Gentleman R, Huber W. Independent filtering increases detection power for highthroughput experiments. Proc Natl Acad Sci USA. 2010;107(21):9546-9551.

41. Schmittgen TD, Livak KJ. Analyzing real-time PCR data by the comparative $C(T)$ method. Nat Protoc. 2008;3(6):1101-1108.

42. Byskov AG. Differentiation of Mammalian Embryonic Gonad. PhysRev. 1986;66(1):71-106.

43. Jepsen MR, Kløverpris S, Bøtkjær JA, Wissing ML, Andersen CY, Oxvig C. The proteolytic activity of pregnancy-associated plasma protein-A is potentially regulated by stanniocalcin-1 and -2 during human ovarian follicle development. Hum Reprod. 2016;31(4):866-874.

44. Mohan S, Farley JR, Baylink DJ. Age-related changes in IGFBP-4 and IGFBP-5 levels in human serum and bone: Implications for bone loss with aging. Prog Growth Factor Res. 1995;6(2-4):465-73.

45. O'connor KG, Tobin JD, Harman SM, Plato CC, Roy TA, Sherman SS, et al. Serum Levels of Insulin-like Growth Factor-I Are Related to Age and Not to Body Composition in Healthy Women and Men. J of Gerontology. 1998;53(3):176-182.

46. Kokk K, Veräjänkorva E, Laato M, Wu XK, Tapfer H, Pöllänen P. Expression of insulin receptor substrases 1-3, glucose transporters GLUT-1-4, signal regulatory protein $1 \alpha$, phosphatidylinositol 3-kinase and protein kinase B at the protein level in the human testis. Anat Sci Int. 2005;80(2):91-96.

47. Neuvians TP, Gashaw I, Hasenfus A, Häcker A, Winterhager E, Grobholz R. Differential expression of IGF components and insulin receptor isoforms in human seminoma versus normal testicular tissue. Neoplasia. 2005;7(5):446-56. 
Figure legends:

Figure 1. Regulation of IGF signaling and the inhibitory effects of stanniocalsin (STC). IGFs are tightly regulated by IGF binding proteins (IGFBPs) that inhibit receptor binding. PAPPA-A cleaves IGFBPs causing release of bioactive IGF, which binds to the receptors IGF1R or INSR and induces intracellular signaling mediated by IRS1 and IRS2. IGF signaling is downregulated by STCs inhibiting PAPP-A. GAG - Glycosaminoglycan.

Figure 2. Effects of fetal age and sex on IGF signalling pathway members. Data was from microarray analysis of 18 ovaries (42-64 pcd) and 28 testes (40-68 pcd). Black arrows above graphs indicate a two-way significant interaction between sex, age and expression levels. Shading illustrate $95 \%$ confidence intervals. Pcd=post conception days

Figure 3. Confirmation of microarray findings for a larger population. Relative transcript levels from q-PCR analysis of 21 ovaries ( $42-133 \mathrm{pcd}$ ) and 34 testes (35-126 pcd) are shown. Black arrows above graphs indicate a two-way significant interaction between sex, age and expression levels. Shading indicate $95 \%$ confidence intervals. Pcd $=$ post conception days

Figure 4. Localization of IGF1R, IGFBP4, IGFBP5, PAPP-A, STC1, and STC2 in embryonic and fetal testes (A) and ovaries (B).The components were located primarily in the Leydig cells in testes, with a weak detection in germ and Sertoli cells, whereas a general expression was seen in the ovary, with a prevalence to germ cells. Scale bars: fetal gonads $=50 \mu \mathrm{m}$, primordial follicle $=20 \mu \mathrm{m}$.

Figure 5. Fluorescent staining of A) PAPP-A together with the Leydig cell marker CYP17 in 17 pcw testis. White arrows indicate Leydig cell staining. PAPP-A was localized in Leydig cells and there was no protein presence within the seminiferous tubules. B) PAPP-A and the germ cell marker LIN28 in an 18 pcw fetal ovary. White arrows indicate a cluster of germ cells. There was a more global localization of PAPP-A in the ovary. PAPP-A was present in some germ cells; however it was also seen in other cell types. ST = seminiferous tubule. 
Table 1. Antibody information

\begin{tabular}{lccccc}
\hline Antibody & Species & Supplier & Cat. No. & Concentration & Dilution \\
\hline IGF1R & Rabbit & Cell Signaling Technology & $3027 \mathrm{~S}$ & $2.6 \mu \mathrm{g} / \mathrm{mL}$ & $1: 50$ \\
PAPP-A & Mouse & $\mathrm{Gift}^{\mathrm{b}}$ & - & $6.4 \mu \mathrm{g} / \mathrm{mL}$ & $1: 100$ \\
STC1 & Mouse & $\mathrm{Gift}^{\mathrm{b}}$ & - & $2.3 \mu \mathrm{g} / \mathrm{mL}$ & $1: 300$ \\
STC2 & Mouse & $\mathrm{Gift}^{\mathrm{b}}$ & - & $2.5 \mu \mathrm{g} / \mathrm{mL}$ & $1: 400$ \\
IGFBP4 & Mouse & $\mathrm{Gift}^{\mathrm{b}}$ & - & $10 \mu \mathrm{g} / \mathrm{mL}$ & $1: 100$ \\
IGFBP5 & Mouse & $\mathrm{Gift}^{\mathrm{b}}$ & - & $6.3 \mu \mathrm{g} / \mathrm{mL}$ & $1: 300$ \\
CYP17A1 & Mouse & Santa Cruz $^{\mathrm{c}}$ & $\mathrm{Sc}-374244$ & $2 \mu \mathrm{g} / \mathrm{mL}$ & $1: 100$ \\
LIN28 & Rabbit & Abcam $^{\mathrm{d}}$ & Ab46020 & $10 \mu \mathrm{g} / \mathrm{mL}$ & $1: 100$
\end{tabular}

${ }^{a}$ BioNordika Denmark A/S, Herlev, Denmark

${ }^{\mathrm{b}}$ Claus Oxvig, Department of Molecular Biology and Genetics - Molecular Intervention, Aarhus University, Aarhus, Denmark

${ }^{\mathrm{e}}$ Heidelberg, Germany

${ }^{\mathrm{d}}$ Cambridge, UK 
Fig. 1 IGF overview

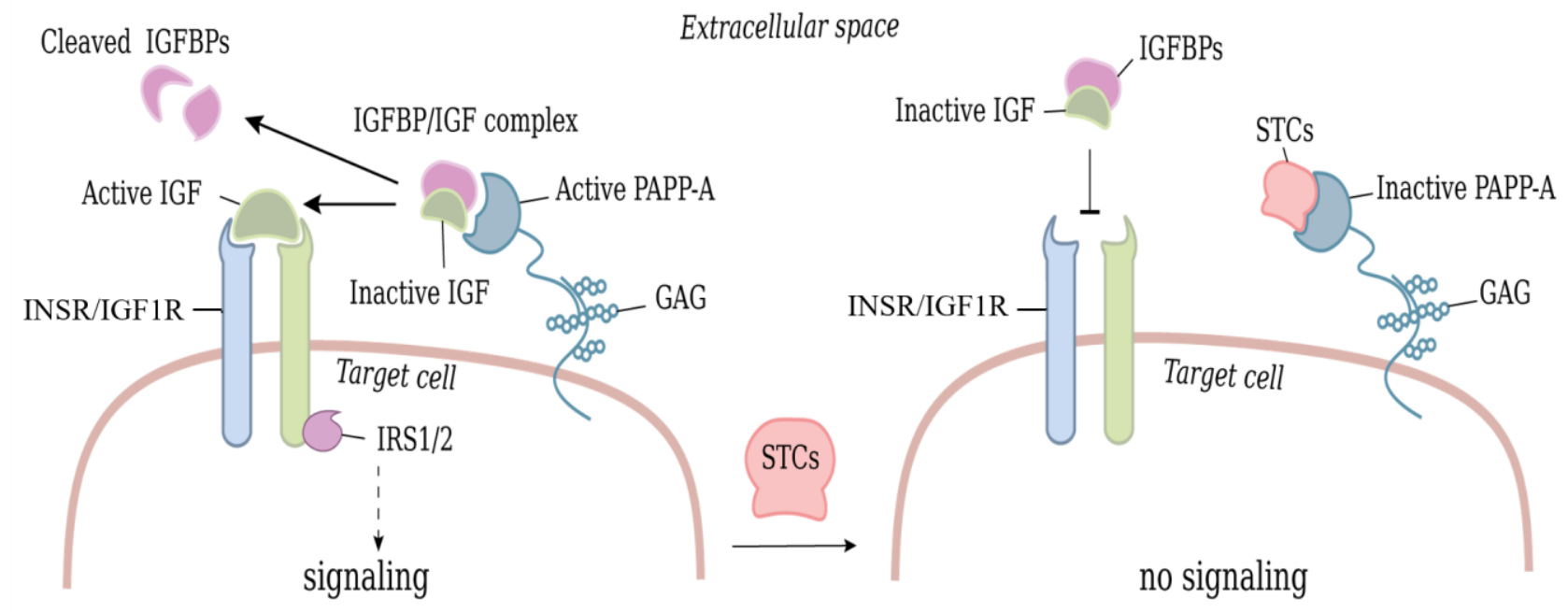


Figure 2 (improved quality)
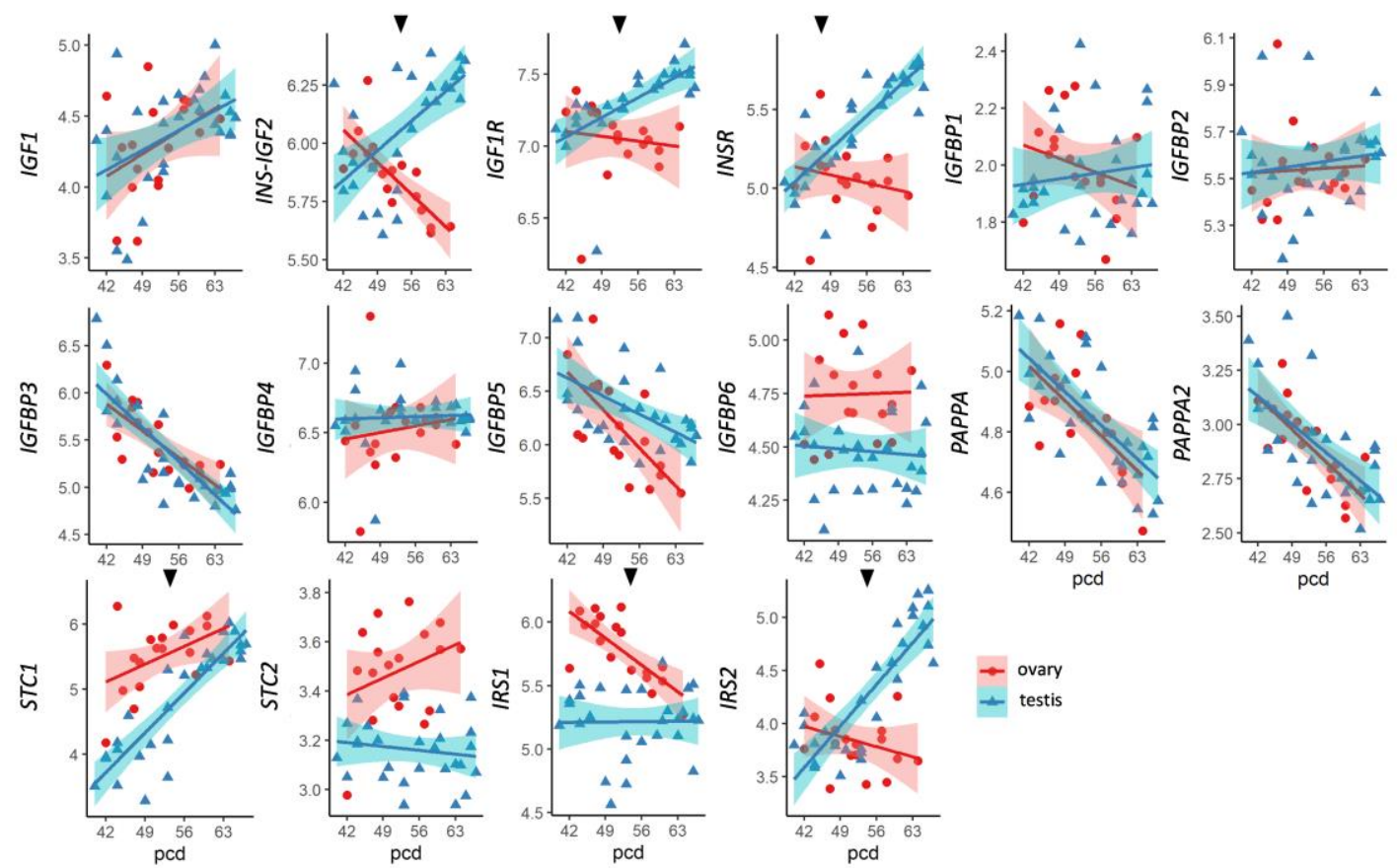
Figure 3 (improved quality)

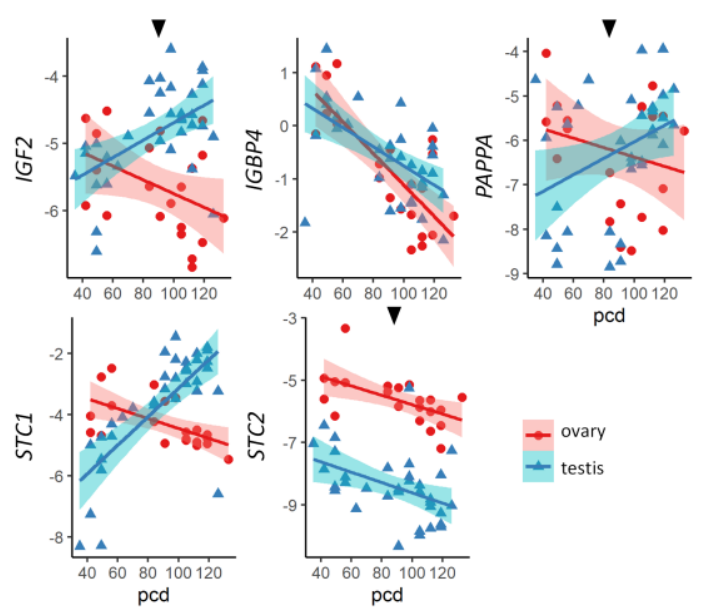


Fig. 4A, IHC testes

\section{A. Testes}

$8 \mathrm{pcw}$
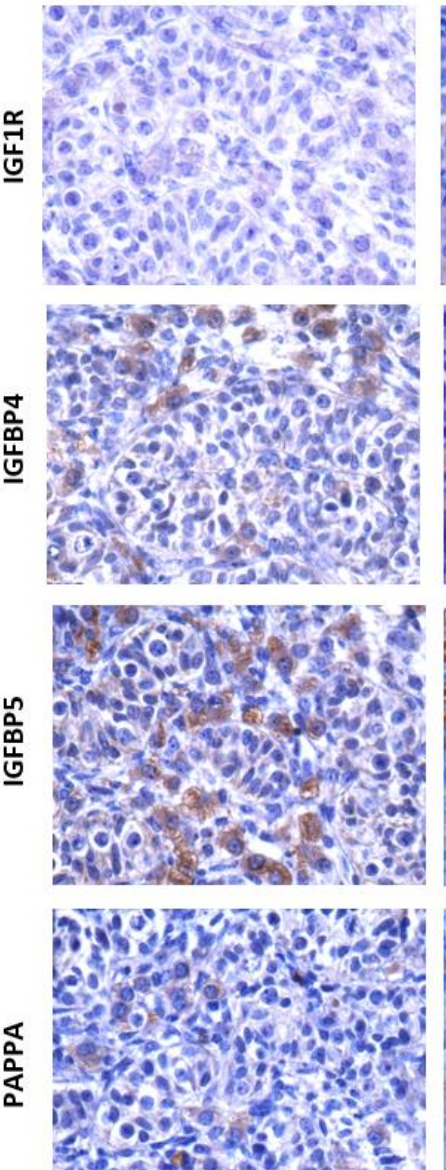

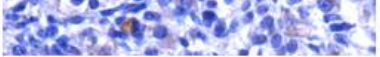
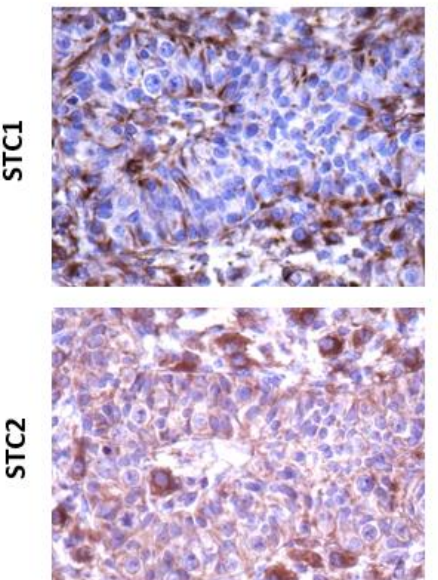

15-16 pcw
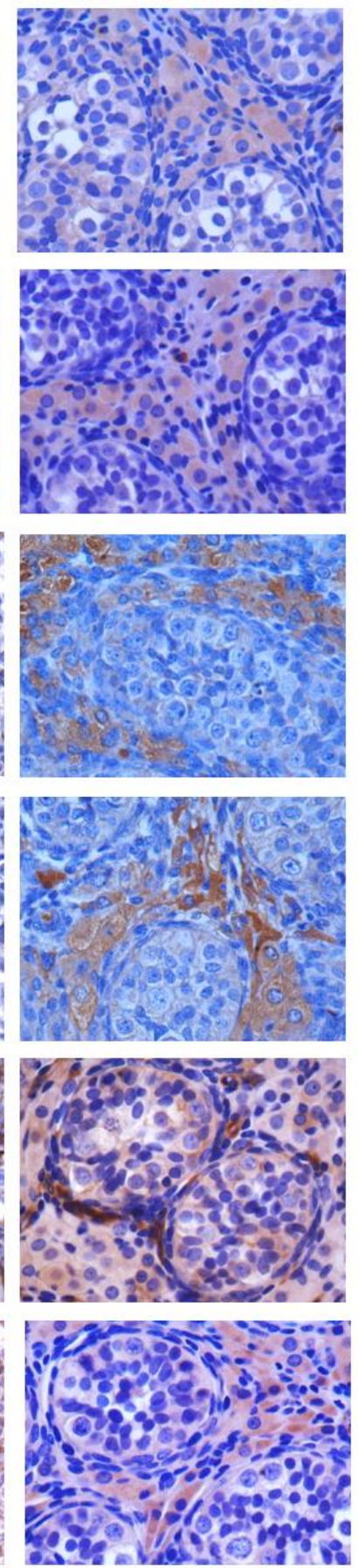

$18 \mathrm{pcw}$
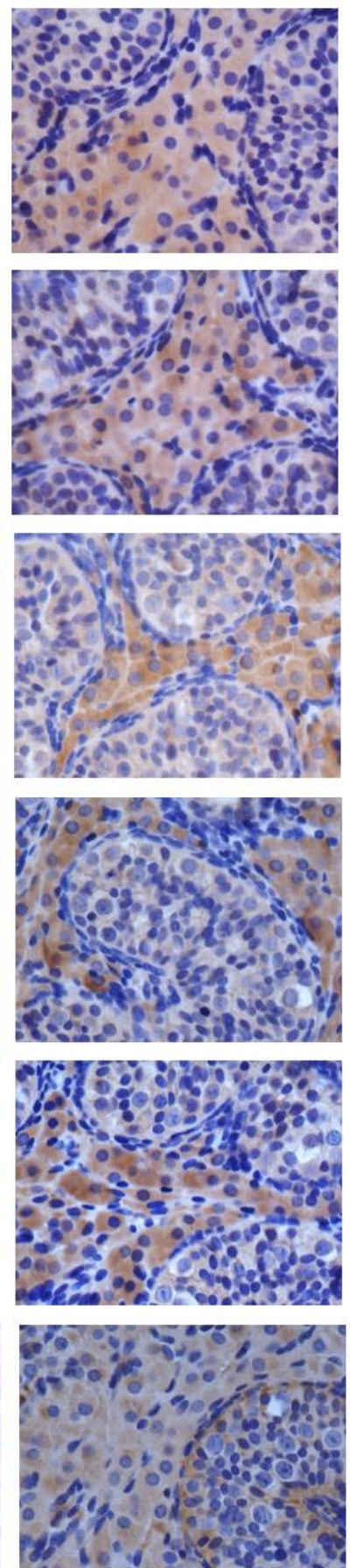

$50 \mu \mathrm{m}$ 
Fig 4B. Ovaries_v2.tiff

\section{B. Ovaries}
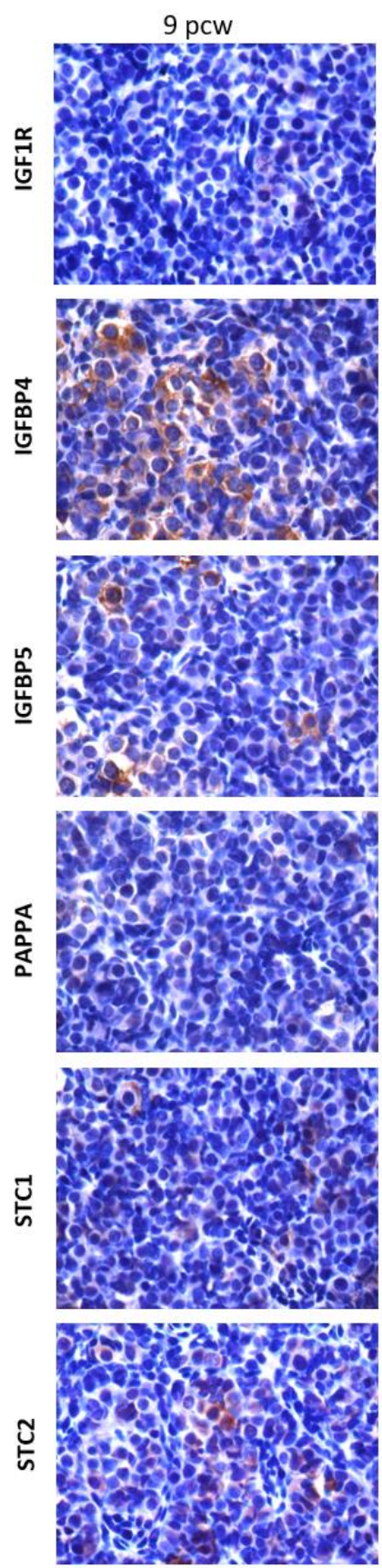

$14 \mathrm{pcw}$
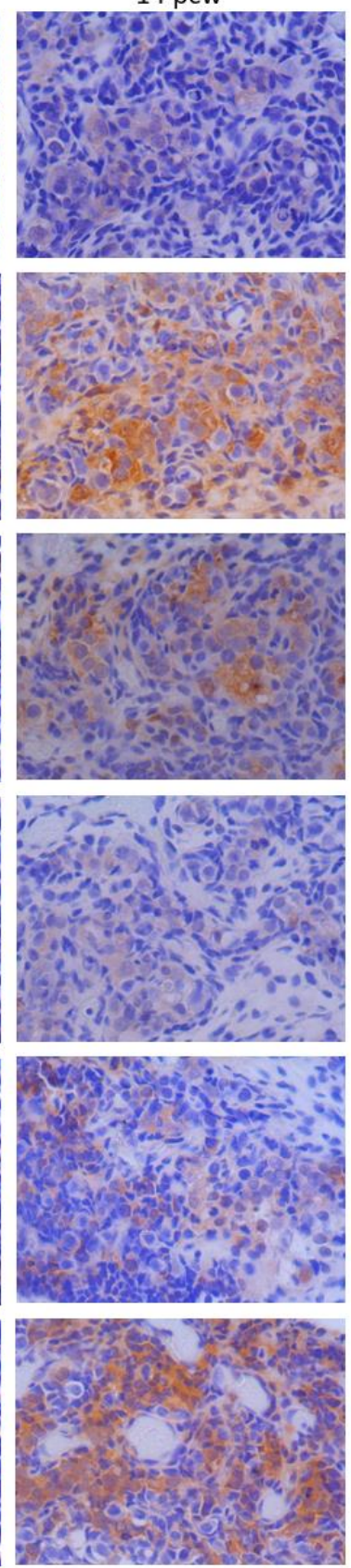

$17 \mathrm{pcw}$
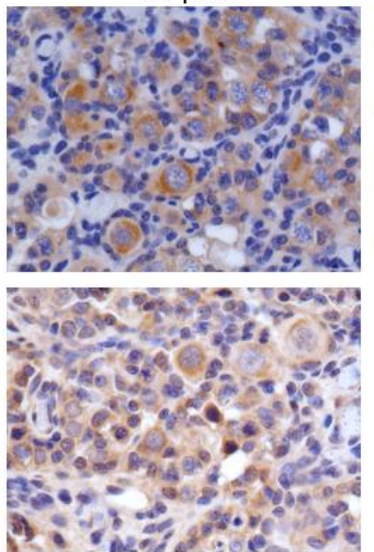

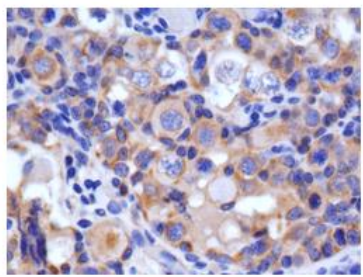
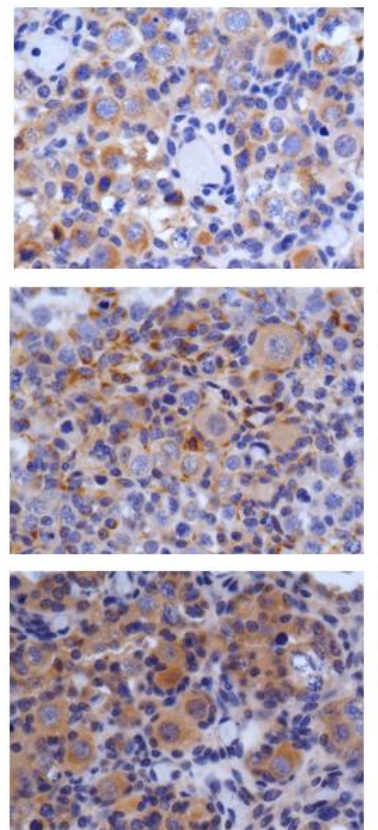

$50 \mu \mathrm{m}$
Primordial follicle
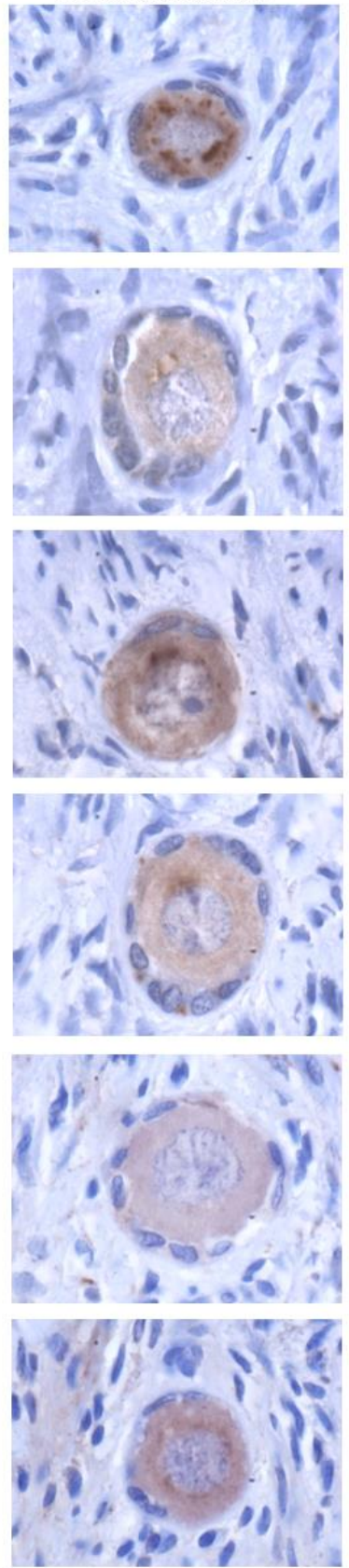

$20 \mu \mathrm{m}$ 
Fig. 5. Fluo figure v3

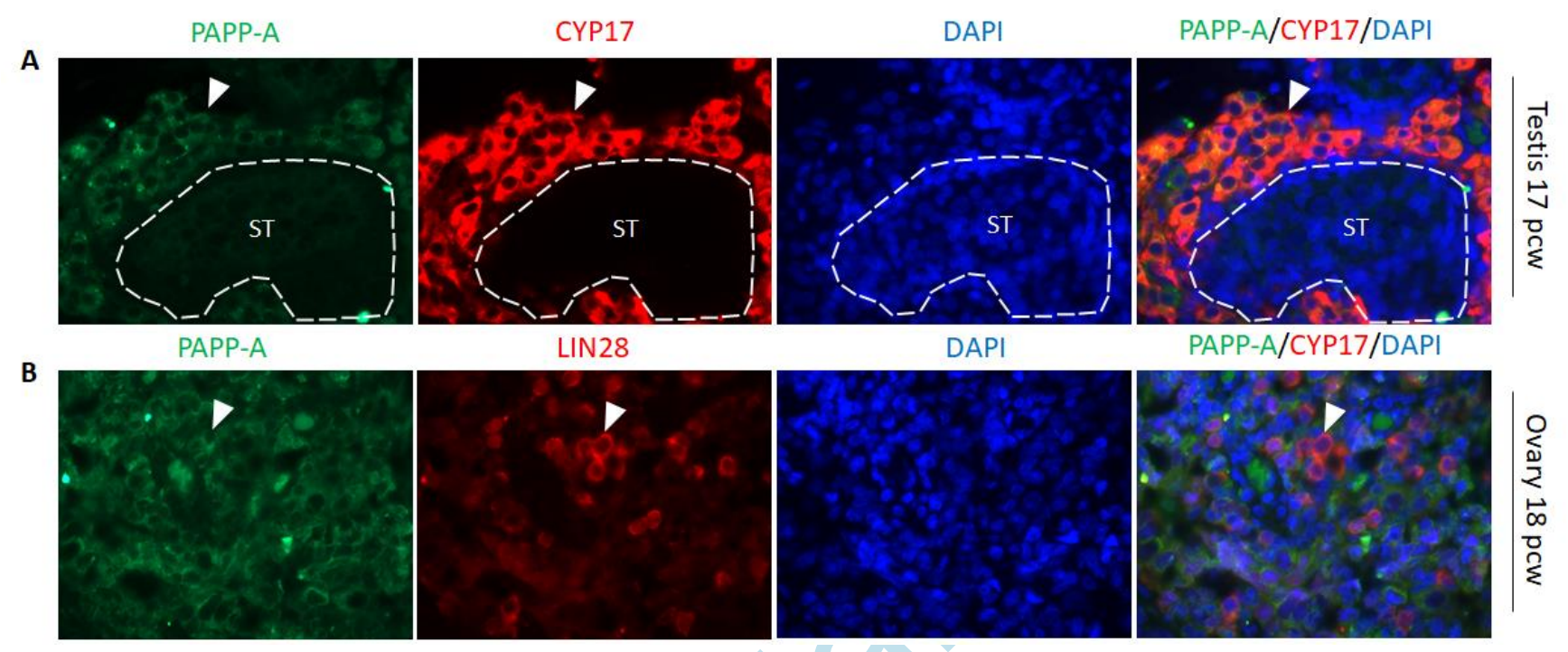

